\title{
Nem só de hormônio vive o homem: representações e resistências de homens transexuais (1984-2018)
}

Júlio Ferro Silva da Cunha Nascimento ${ }^{1}$ Universidade Federal do Pará

RESUMO: Em 1984 é publicada a autobiografia Erro de pessoa, escrita por um homem trans chamado João W. Nery, por anos a única referência brasileira sobre transmasculinidade. Hoje em dia, além do livro, existem as redes sociais e sites de compartilhamento de informação, que podem abordar as transmasculinidades plurais. O intuito do presente artigo é analisar as representações e resistências de homens trans em jornais da década de 1980, entrevistas, site de compartilhamento de vídeos Youtube e redes sociais, analisando permanências e descontinuidades de 1984 a 2018.

Palavras-Chaves: transmasculinidade; periódicos; representatividade. 


\title{
Man shall not live by hormones alone: representation and resistances of transexual men (1984-2018)
}

\begin{abstract}
In 1984 the autobiography of a trans man called João W. Nery, Erro de pessoa, that for years was the only Brazilian reference on transmasculinity, was published. Nowadays, in addition to the book, there are social networks and information sharing sites, which can address plural transmasculinities. The purpose of the present article is to analyze the representations and resistances of trans men in newspapers of the eighties (1980's), on the video sharing site Youtube and social networks, analyzing permanences and discontinuities from 1984 to 2018.
\end{abstract}

Key-words: transmasculinity; newspapers; representativity.

\section{No sólo de la hormona vive el hombre: representación y resistencias de hombres transexuales (1980-2018)}

\begin{abstract}
Resumen: En 1984 se publica la autobiografía de un hombre trans llamado João W. Nery, Erro de pessoa, que por años era la única referencia brasileña sobre transmasculidad. Hoy en día, además del libro, existen las redes sociales y sitios de intercambio de información, que pueden abordar la transmasculinidades plurales. El objetivo del presente artículo es analizar las representaciones y resistencias de hombres trans en periódicos de la década de los ochenta (1980), en el sitio de intercambio de vídeos Youtube y redes sociales, analizando permanencias y discontinuidades de 1984 a 2018.
\end{abstract}

Palabras clave: transmasculinidad; periódicos; representatividad. 
$\mathrm{O}$ estudo da transexualidade confronta moldes corpóreos e acadêmicos ao questionar conceitos tradicionais de corpo e gênero através da chamada Teoria Queer, que tem em Judith Butler um de seus expoentes. Pesquisadores, geralmente, tendem a produzir textos onde generalizam a transexualidade ao tentar conceituá-la, identificando padrões que sustentam a sua problemática. A riqueza dos "temas trans" está na pluralidade, porém, tal atitude acadêmica empobrece a pesquisa, pois ignora que a transexualidade possui não apenas continuidades, mas também quebras, além de não levar em consideração os modos diversos de uma pessoa se entender enquanto transexual, enquanto determinado gênero e expressão de gênero (NASCIMENTO, 2018).

Vale questionar o discurso científico sociobiológico a respeito de corpos trans, onde entende-se sexo como a classificação de caráter biológico com base em elementos orgânicos como cromossomos, níveis hormonais, órgãos produtivos e genitais (JESUS, 2012). Tal pensamento é negado pela Teoria Queer por encarar o sexo como uma construção social que se pretende biológica e neutra, que há séculos é ligada a um cientificismo que "comprova" se alguém é "homem de verdade" ou não, em um caráter biológico frequentemente arbitrário (BUTLER, 2011). A noção de sexo passa por influências culturais, como o terceiro sexo indiano (NAPHY, 2004) e, por contradição, se depara com corpos que fogem de uma tradição macho ou fêmea, a exemplo, os intersexuais (MACHADO, 2008).

Embora crescente, os estudos de "temas trans", em sua maioria, abordam a trajetória e militância de mulheres trans e travestis. Já os homens trans ${ }^{2}$, frequentemente, são pesquisados apenas quando o assunto é estudar a comunidade transexual em geral. No Brasil, a abordagem específica a respeito da transmasculinidade é recente para as ciências humanas (LEITE JR., 2011), iniciada nos anos de 2010, diferente dos estudos da transfeminilidade, datadas desde 1990.

Posto isso, torna-se relevante a pesquisa a respeito da representação da transmasculinidade, uma vez que o "silêncio" sobre essa comunidade acaba por manter preconceitos a respeito de homens trans, mas, também, a sua invisibilização de classe (VERAS, 2015). Além da representação, é interesse estudar resistências transmasculinas devido estas alterarem como são representados e se representam nas artes, nas redes sociais e trabalhos acadêmicos, com relatos coletados em entrevistas presenciais, relatos on-line e autobiografias de homens trans.

\section{Entrevistas do passado e do presente}

Utilizando a ferramenta de busca da Hemeroteca Digital da Biblioteca Nacional, foi possível encontrar notícias presentes nos periódicos de 1980 a respeito de João W. Nery, um escritor ativista transexual que causou impacto com o lançamento de sua autobiografia, publicada em 1984. As notícias tendem a focar na

${ }^{2}$ Homem transexual é o sujeito que, ao nascer, foi designado mulher com base na existência de vulva, mas, ao longo de sua vida, entende-se enquanto homem. 
questão cirúrgica ou nos hormônios da vivência transmasculina, propensão ligada ao sensacionalismo, comum em reportagens que focam na parte que possui mais chance de chamar a atenção do leitor. Cirurgias e o uso de hormônios são presenças marcantes em matérias jornalísticas até hoje, o que diminui as vivências trans às questões médicas e farmacêuticas.

Os jornais encontrados da década de 1980 que abordaram a obra de João W. Nery são Folha de São Paulo (SP), Jornal do Commercio (RJ), Jornal do Mato Grosso (MT) e o Jornal do Brasil (RJ). Nas matérias, é possível notar o impacto que sua obra causou: jornalistas começam a escrever sobre homens trans, embora sendo comuns os casos de "o homem que nasceu mulher" ou "a mulher que virou homem". Entendo esta tática como maneira de fazer o leitor ou leitora leigos entenderem, mesmo de maneira simplória, o que é transexualidade, levando-os a se interessarem em ler a obra.

De todas as fontes de periódicos, apenas a Folha de São Paulo dedica mais que uma pequena coluna a João W. Nery, sendo uma matéria de meia página, com uma entrevista ao escritor a respeito de sua trajetória enquanto homem transexual. É notável a preocupação do jornalista em pesquisar sobre o assunto e defender direitos transexuais como a descriminalização das cirurgias de transição de gênero e a mudança de nome e de gênero do indivíduo. Nery realizou as cirurgias e a mudança de nome e de gênero ilegalmente, fato encarado como necessário devido a um atraso 3 da sociedade brasileira em acolher pessoas transexuais:

\begin{abstract}
Como consequência, a marginalização do indivíduo se torna inevitável. Consciente de sua esterilidade após a cirurgia de conversão e de sua incapacidade de se "deleitar com o prazer orgástico", ainda assim João Nery decidiu se insurgir contra a estupidez das regras sociais e jurídicas, optando pela cirurgia. (FOLHA DE SÃO PAULO, 1985: 27)
\end{abstract}

No presente trabalho, a pesquisa da trajetória de João W. Nery pode ser justificada devido ao fato de Nery fazer questão de "levantar a bandeira" do movimento social ao qual pertence. Infelizmente, existe a dificuldade notável de outras referências transmasculinas pré-século XXI, fator que ligo a duas questões principais: jornais que preferem abordar narrativas transfemininas e a outra é a "passabilidade cis" 4 (ALMEIDA, 2012) que homens trans conseguem alcançar.

As características corporais do estereótipo masculino para um homem trans em processo de transição são mais fáceis de serem adquiridas do que as femininas, portanto, homens trans são lidos de forma masculina mais fácil que travestis que procuram adquirir uma leitura social feminina. Por isso, muitos homens trans preferem "se misturar na multidão" do que atuar em grupos de militância, atitude agravada devido à transfobia que leva muitos a evitarem o desgaste emocional de assumirem-se abertamente como transexuais (ALMEIDA, 2012).

Além das fontes escritas, foram realizadas entrevistas com cinco homens transexuais paraenses para entender as suas situações num âmbito local e atual, onde os mesmos relataram sobre os frutos da militância transmasculina na cidade de Belém, os obstáculos sociais e familiares impostos sobre a sua sexualidade, procedimentos médicos e o reconhecimento enquanto homem.

Um dos entrevistados, Fernando5, branco, morador de periferia, classe média baixa, 21 anos, universitário, comenta que, desde a infância, a discriminação faz parte de sua vida: isso porque tal infância foi marcada por exclusão por ele ser

\footnotetext{
3 "Atraso" comparado com países como Estados Unidos que, desde a década de 1960, possui casos de pessoas que fizeram "conversão sexual" amparadas por tribunais (CASTEL, 2001).

4 Termo que se refere à capacidade de uma pessoa que é trans ao adquirir características ligadas ao seu gênero, de ser lida, socialmente, pelo gênero que se identifica. Como, por exemplo, um homem trans, que ao ter barba e voz grave, pode ser visto como um homem cis por se enquadrar no estereótipo masculino.

${ }_{5}$ Nome fictício para preservar a identidade do entrevistado.
} 
sempre o "estranho" que não se identificava com as meninas e era excluído pelos meninos. Conforme o passar dos anos, o desejo de assumir roupas masculinas e cabelo curto amadurecia, tanto que, aos 12 anos, Fernando cortou o cabelo e assumiu roupas masculinas: "pra mim, isso foi como uma terapia; pra minha família, um pesadelo".

Geralmente, os entrevistados apenas adotavam cortes de cabelo curto na fase adulta, mas Fernando comenta que durante boa parte da sua infância possuía cabelo curto, pois havia criado determinada estratégia: comum em muitas escolas, as crianças praticavam o bullying de pôr chiclete no cabelo das outras, mas Fernando teve a ideia de apelar para esse comportamento de "criança" e chegar em casa cheio de chicletes presos no cabelo, sem contar para a família que quem pregou as gomas de mascar foi ele mesmo, obrigando a mãe a cortar o seu cabelo.

\section{Do papel para a Internet}

Segundo Simone Ávila (2014), a emergência de homens transexuais no cenário ativista LGBT+ brasileiro é datada apenas por volta de 2010 com o surgimento de organizações voltadas, nacionais e estaduais, em específico para questões transmasculinas. A autora defende que o crescimento da participação transmasculina em termos de militância é ligada ao crescimento da visibilidade de homens trans na mídia, com personagens homens trans em séries e o caso do "primeiro homem grávido"; o crescimento do uso da internet dentre a população brasileira nos anos de 2010 possibilitou o contato entre homem trans em comunidades online, blogs e sites; e quebrar com anos de isolamento político de homens transexuais em passeatas e organizações no movimento transexual brasileiro (ÁVILA, 2014).

Entre os entrevistados, o site de compartilhamento de vídeos chamado Youtube é entendido como principal fonte de informação sobre assuntos pertinentes à comunidade transexual, como identidade de gênero, o processo de assumir-se, como e onde se hormonizar, entre outros assuntos. O grande diferencial da plataforma é que ela permite a publicação de vídeos feitos por homem trans para homem trans - embora maioria do sudeste brasileiro ou de fora do Brasil -, sem o intermédio de uma pessoa cis como um jornalista ou acadêmicos que sejam cisgêneros, como fala Rodrigo:

Todas as referências que eu tinha de homem trans eram principalmente estrangeiras e dificilmente eram daqui do norte, eram mais sul e sudeste, né? Então todas as informações iniciais que eu tive foi por conta da internet, enfim, foram por conta desses homens trans que já tavam aí no Youtube, por exemplo. Conheci também a história do João W. Nery por conta da internet.

Lucca Najar é um criador de conteúdos para o Youtube que produz vídeos em torno de temáticas transexuais, geralmente falando da sua própria transmasculinidade. Com cerca de 90 mil inscritos no seu canal, chegando a possuir um vídeo de quase meio milhão de visualizações, Najar ganhou notoriedade na comunidade e na mídia, tanto que um de seus vídeos apareceu na novela $A$ Força do Querer (2017), que bateu recordes de audiência.

A publicação on-line de vídeos produzidos por homens trans para homens trans, "nós por nós", representa bem a difusão de informação na presente década, pois, além da importância de se informar sobre procedimentos médicos, é também importante que quem produz participe da comunidade transexual, afinal, os vídeos mais comuns são vídeos sobre como o próprio youtuber passou pela tran- 
sição de gênero, como a família o tratou ou o trata, seus relacionamentos amorosos enquanto transmasculino, entre outros temas, o que pode ser visto como uma questão de protagonizar a produção de conhecimento sobre assuntos trans.

Porém, paralelamente, torna-se possível questionamentos a respeito do alcance da representação transmasculina. Pois, é perceptível a presença da branquitude e de elementos masculinos como fatores comuns entre os homens trans na cena youtuber. Lucca Najar, Jackson Bird, Téhh Queiroz, Chase Ross, Luca Scarpelli são donos dos vídeos com maiores taxas de visualização a respeito de homens trans no Brasil e mundo afora, sendo todos homens transexuais magros, brancos e que passaram por cirurgia de retirada dos seios. Embora seus marcadores sociais ligados a privilégios sociais não diminuam a sua importância enquanto militantes trans, é possível entender uma invisibilização negra dentro da comunidade transmasculina.

A historiografia tradicional prioriza fontes físicas, no entanto, nas últimas décadas, abraçou o uso de fontes orais. Mas o uso de fontes digitais ainda é raro e pode ser encarado com desconfiança, impulsionada pela rápida temporalidade e falta de credibilidade que elas podem apresentar (DE ALMEIDA, 2011). Porém, para a produção deste artigo, tornou-se essencial o uso de fontes digitais, devido ao fato de ser unânime entre os entrevistados o uso da internet na construção da sua identidade, mas, também, na fala de garotos e homens trans entrevistados em reportagens e documentários.

Em termos de estudos trans e outros temas, o erro de negar a importância da internet e da mídia na vivência de quem é entrevistado ou entrevistada prejudica a pesquisa (ARAÚJO, 2014). As redes sociais e sites de compartilhamento de vídeos online provam-se presentes na construção de sujeitos políticos que frequentemente levam a militância desses espaços para as ruas, coletivos, projetos sociais, assim por diante.

\section{Homem sim, trans também, hormônios à parte}

Uma questão mais do dia a dia da comunidade transmasculina é a chamada "passabilidade cis", que é uma forma de pessoas trans conseguirem exercer estéticas e comportamentos esperados, neste caso, apenas de sujeitos homens, mas com menores ou sem riscos de constrangimentos, podendo haver a possibilidade do uso de elementos masculinos que determinado sujeito trans não chega a gostar, mas utiliza para melhor misturar-se na multidão ou emanar respeito, como ir frequentemente à academia.

Entendo que o uso de elementos culturais ditos masculinos como um fator identitário transmasculino altera a natureza do elemento. Por exemplo, usar trajes de basquete que são folgados pode ser algo passado em branco por homens cis, mas para homens trans pode ser uma forma de esconder o volume dos seios. Logo, pode-se notar um fator político-social ligado ao que seria um simples ato cotidiano.

A relação entre o sentido político-social em atos ditos masculinos exercido por homens trans pode ser bem mais claro quando o assunto muda para o uso de hormônios e cirurgias, uso tão ligado à comunidade transexual que o senso comum leva a entender que é o que se resume ser trans e que pessoas cisgêneros não realizam esses procedimentos médicos (TUSSI, 2006).

Existem homens cisgêneros que realizam a retirada de glândulas mamárias excessivas. As glândulas não causam complicações médicas, mas são retiradas devido ao paciente acreditar ser de grande importância para sua qualidade de 
vida (DAVANÇO, 2004). O homem cisgênero que realiza esse procedimento médico não é homem apenas após a cirurgia, ele já possui uma identidade de gênero masculina e a cirurgia foi uma forma de viver a sua masculinidade e evitar futuros constrangimentos. Portanto, um homem que é trans também já é homem antes da cirurgia.

Homens cisgêneros na andropausa podem procurar o uso de testosterona por considerar importante para a imagem que têm de si mesmos (ROHDEN, 2011). O homem cisgênero continua homem antes e depois do tratamento, não é a testosterona que determina seu gênero, o papel da testosterona é ajudá-lo a viver à sua maneira de ser homem, assim como o homem transexual que opta pelo tratamento hormonal.

Dessa forma, pode-se refletir sobre o seguinte questionamento: transição é o ato de tomar hormônios ou de realizar cirurgia? Nenhuma das duas opções. Encaro como uma questão identitária: no caso dos homens trans, é o ato do indivíduo se entender como homem e passar a viver o seu gênero homem e não o gênero mulher, que o era imposto. Este entendimento do que se caracteriza um homem é capaz de sofrer alterações em um processo de constante alteração conforme sua vivência, assim como acontece com homens cis (GASPODINI, 2017). Portanto, a transmasculinidade é uma identidade e não um procedimento clínico.

Seja por escolha própria, pressão social ou a comum mistura das duas, os procedimentos médicos de hormonioterapia, cirurgia de redesignação sexual, retirada do útero e mastectomia masculinizadora possuem um custo elevado, sendo necessário estabelecer nesta pesquisa a relação desses fatores com a renda e etnia dos homens que são transexuais.

Posto isso, utilizamos os relatórios do Ipea, FJP e Pnud que produzem estatísticas a respeito da divisão de renda entre os brasileiros de acordo com fatores como gênero, etnia e localidade (rural ou urbana), tornando-se uma fonte útil para relacionar o fator de renda e etnia com a possibilidade de transição através de hormônios e/ou cirurgia. Segundo os relatórios de 2017, a população negra recebe menos da metade $(\mathrm{R} \$ 508,90)$ que a população branca $(\mathrm{R} \$ 1.097,00)$, o que dobra a dificuldade à aquisição de testosterona injetável, retirada das mamas ou cirurgia de redesignação sexual.

A popularização da pílula anticoncepcional no Brasil, nos anos 80, trouxe a possibilidade de adquirir hormônios artificiais com frequência, preço acessível e sem burocracia, onde mulheres trans e travestis podem usufruir para, assim, produzirem mudanças no próprio corpo (LEITE JR, 2011). Embora seja perigoso o uso da automedicação, este comportamento foi a estratégia encontrada por essas pessoas de poder viver seu gênero.

Diferentemente do estrógeno e da progesterona, o hormônio testosterona não é encontrado com facilidade e baixo preço em farmácias. Além disso, é preciso ter uma receita médica para realizar a compra. Devido à discriminação transfóbica em espaços de saúde (MÜLLER, 2007), alguns homens trans optam pela compra de "receitas frias", mas esse quadro tem mudado com as políticas públicas de aceitação às pessoas transexuais e travestis, como a criação de ambulatórios específicos para o acolhimento de pessoas trans que procuram tratamento hormonal ou cirurgias através do Sistema Público de Saúde (SUS).

O Pará é o primeiro estado do Norte do Brasil a possuir um Ambulatório de Transgêneros, localizado no Hospital Jean Bittar, que começou seus atendimentos em 2017. Vários entrevistados frequentam ou já frequentaram o ambulatório e elogiam o atendimento realizado pelos profissionais do local, que são assistentes sociais, psicólogos, endocrinologistas, cirurgiões, entre outros (PIMENTEL et 
al., 2018). A iniciativa é defendida pela coordenadora do ambulatório, a endocrinologista Flávia Cunha, que defende a importância do projeto na manutenção da saúde e da vida de pessoas trans, as quais possuem preocupantes índices de quadros depressivos (TOOMEY et al., 2018).

A endocrinologista detalha o procedimento de hormonioterapia, começando pelo acolhimento psicológico dos pacientes, em que são realizadas sessões de terapia para melhorar a sua saúde mental, diminuindo quadros de ansiedade e depressão e, também, para “diagnosticar a disforia de gênero". Depois disso que é realizada a hormonização e, apenas depois de dois anos da hormonização, é que são permitidas as cirurgias, no caso dos homens trans, de mastectomia masculinizadora e/ou de redesignação sexual.

Caso a pessoa opte pela saúde privada para realizar a cirurgia de redesignação sexual, será necessário arcar com, em média, 45 mil reais, além dos gastos com acompanhamento psiquiátrico de dois anos e possíveis complicações médicas. A cirurgia mais barata e mais comum é a de mastectomia masculinizadora, que gira em torno dos 8 mil reais, mas sem contar o custeio de permanência no hospital no pós-cirúrgico, um colete que ajuda na cicatrização e retirada de fluidos, antibióticos, curativos, possíveis complicações médicas, tudo isso podendo elevar o preço para acima de 15 mil reais 6.

Inclusive, quem não depende do Sistema Único de Saúde e que possui capacidade econômica de comprar frequentemente hormônios passa pela dificuldade de encontrar injeções de testosterona em farmácias. Daniel, um dos entrevistados, comenta sobre ir em mais de 26 farmácias, por Belém e por Ananindeua, à procura do medicamento, sendo comum ficar sem testosterona injetável por não ter onde comprar, ou, quando está disponível no estoque, pelos valores pessoais dos atendentes:

Uma vez eu já cheguei a sair de casa de manhã e voltei às gh3o da noite. Eu tinha ido em 26 farmácias (...) e não tinha, lugar nenhum (...) e tem o problema de rejeitar a receita, acontece bastante isso. A pessoa (atendente da farmácia) não querer atender, ela vê do que é e pra que é e ela não quer atender, aí a gente não tem como pegar (...) aí tem essa convicção do atendente, que a gente fica sem porque ele não quer vender.

As dificuldades aqui apresentadas ajudam a desmistificar concepções a respeito da relação das pessoas trans com hormônios, pois ao contrário do que o senso comum afirma, o processo de hormonização não é tão comum entre pessoas trans (TUSSI, 2006), pois boa parcela não consegue se hormonizar devido a fatores de renda, oferta do mercado e/ou falta de políticas públicas sobre saúde trans.

Berenice Bento (2006) aborda a trajetória da construção de discursos patologizantes em torno de sujeitos desviantes de normas sociais em torno de corporalidade e sexualidade, sendo as pessoas trans e travestis entendidas enquanto uma máxima desse "desvio". No início do século XX, acontece o crescimento do discurso cientificista em torno de corpos e comportamentos ligados, fortemente às concepções conservadoras moralistas do período. Assim, as pessoas que procuravam viver um gênero diferente do designado ao nascer começam a ser entendidas enquanto "doentes" que precisam voltar exercer seu "gênero de nascimento": na metade do século XX, com o endocrinologista Henry Benjamim, que entende que a pessoa não está doente, mas "precisa" de cirurgias para acabar com

${ }^{6}$ Valores monetários segundo homens trans que realizaram os procedimentos e abordam online o processo de determinada cirurgia (Lucca Najar, Paulo Vaz e Christian Silva, famosos por abordar temas transmasculinos, relacionando com a sua própria vivência). 
uma "disforia de gênero; e, hoje em dia, embora ainda exista o discursos patologizantes e essencialistas em torno das comunidades trans em espaços institucionais, cresce a presença de discursos militantes de organizações como a Stop Trans Pathologization, que repercutem nos meios de comunicação a respeito de como pessoas trans e travestis não precisam de cura, mas de direitos assegurados (BENTO, 2012).

Outra concepção perigosa é a de que pessoas trans são forçadas a se hormonizar pela ideologia de gênero (MISKOLCI, 2017), ou "seduzidas pelo patriarcado a performar masculinidade" (RAYMOND, 1979), ou por pura estética. Com o levantamento de dados, realização de entrevistas e bibliografia do assunto, entende-se que a hormonização é principalmente ligada à saúde mental do homem trans, que vê na testosterona não a cura para todos os problemas, mas uma ferramenta útil para validar seu gênero, ser mais aceito pela sociedade e na esfera particular, diminuir certas frustrações, fatores que consequentemente contribuem para enriquecer a saúde mental do indivíduo, diminuindo a preocupante taxa de suicídio na comunidade transmasculina (TOOMEY et al., 2018).

\section{Identidades furtivas}

Na sua mais recente autobiografia, João W. Nery escreve um capítulo chamado "Encontro das cobaias" sobre uma reunião com três amigos que são homens transexuais e que estão na terceira idade, exceções entre as pessoas trans. Esse relato é persistente para a análise por adicionar marcadores de idade e época para o debate.

Chamados de "cobaias" devido ao fato de todos terem realizado a mastectomia masculinizadora e a retirada do útero na última década do século XX, assim como João, escondidos das autoridades, pagando ou convencendo um amigo médico a realizar a cirurgia ainda em fase de testes na época. E sobre os documentos de identidade, todos precisaram ser adquiridos de forma ilegal, pois o Estado negava-se a mudar o nome e o gênero de Nery e amigos.

Diferentemente de João e seus amigos, os entrevistados para essa pesquisa estão na faixa etária de 18 a 28 anos e, devido ao fruto da militância de outras pessoas trans e aliados, o nome escolhido pelo sujeito ganha legalidade e já podem realizar cirurgias específicas sem precisar ser escondido, necessitando apenas de um laudo médico arbitrário para quem realizará a cirurgia, ou seja, o laudo só é solicitado se o médico ou médica acreditar ser necessário.

Os senhores amigos de Nery comentam que a transexualidade não os impediu de exercer a paternidade, pois todos são pais há décadas de filhos adotivos, com o filho ou a filha sabendo ou não. Mas a questão da adoção não é o único segredo, é unanimidade entre os amigos a permanência da transexualidade "no armário" 7 por terem medo ou não verem necessidade de assumirem-se para os filhos. $\mathrm{Na}$ roda de conversa, Nery era o único assumido para todos seus conhecidos, incluindo o filho.

Entre os cinco homens trans entrevistados, todos são assumidos a respeito do seu gênero, transexualidade e sexualidade e eles encaram ser assumido como uma necessidade para uma autoaceitação e, também, por agregar um valor político em se assumir e lutar por direitos trans. Porém, o fato de todos eles serem assumidos não pode ser encarado como regra, seria mais apropriado encarar como exceção, pois para os próprios entrevistados se assumir foi um processo

7 Gíria que se refere a pessoas da comunidade LGBT que não assumiram a sua sexualidade ou identidade de gênero, seja entre certos grupos pessoais ou publicamente. 
complicado na esfera pessoal e familiar, que se tornou possível apenas pelo apoio da família e/ou de amigos, mas que, infelizmente, é raro de existir para a maioria da população transexual e travesti.

Por não entrevistar nenhum homem trans não assumido, perguntei para os participantes sobre homens e garotos trans que não se assumem, pelo menos para a maior parte das pessoas do seu âmbito social e, ainda, os motivos pelos quais eles acham que isso acontece. Os relatos apontam para diferentes motivos, mas que se conectam: o medo de perder laços familiares e de amizade, do desemprego, de não validarem seu gênero, entre outras razões.

A pesquisa aponta para a existência de indivíduos transmasculinos que utilizam o ganho de características físicas como barba, voz grave e ausência de seios como uma maneira de "abaixar a bandeira trans" ou preservar sua saúde mental e assumir uma identidade que nega a transexualidade, como se o indivíduo sempre fosse um homem cisgênero.

Nas mulheres trans e travestis, os hormônios utilizados podem prevenir ou diminuir características tidas como masculinas, como o crescimento de pelos e voz grave. Porém, mudanças como a estrutura do maxilar e o pomo de adão são reversíveis apenas com cirurgias, em geral, caras e dolorosas. O ganho de características masculinas pelos homens trans, comparada a das mulheres trans e travestis, é mais rápida e podem ser obtidas apenas com hormônios e o uso de binder, que é uma peça de roupa que prensa os seios para dar uma aparência de torso reto (ALMEIDA, 2012).

A maior facilidade de adquirir a "passabilidade cis", ou então de ser lido como homem cisgênero que o homem trans possui, é um dos motivos para o baixo registro de fontes a respeito de sua existência. As fontes mais comuns sobre mulheres trans e travestis eram em notícias que mostravam mortes por transfobia (EIGA e GUZZO, 2016). Essas notícias negativas podem ser interpretadas como motivos para não se assumir, pois, por que correr riscos? Por que virar estatística?

Mesmo sendo um homem transexual assumido, o ativista americano Jackson Bird consegue entender os motivos para muitos de seus colegas de comunidade ainda esconderem a sua faceta transexual, seja para a família, família dos parceiros, colegas de classe, no trabalho e assim por diante. Isso porque a própria invisibilidade social que homens trans possuem, onde até possíveis agressores não sabem nem da existência dessa categoria de homem, é usada como defesa por esses homens trans.

Mulheres trans e travestis possuem uma certa visibilidade construída ao longo das décadas. Elas estão desde os anos 70 em shows, em jornais, na televisão, em livros e filmes (OLIVEIRA, 1997). Porém, essa visibilidade atrai a visão de pessoas conservadoras e violentas que repudiam a existência de pessoas nãocis. Por que a mídia representa mais mulheres trans e travestis do que homens trans? Segundo a bióloga e ativista Julia Serano (2016), homens trans são despercebidos ou ignorados pela mídia devido a esta ser incapaz de sensacionalizar homens trans do mesmo jeito que faz com mulheres trans sem questionar o que seria masculinidade, mas, também, devido aos leitores entenderem o porquê de alguém querer adquirir privilégio masculino (homens trans), mas não compreenderem motivos para abrir mão do tratamento enquanto homens (mulheres trans).

O termo "stealth" significa, em português, "furtividade", no sentido de estar disfarçado, e serve para se referir a pessoas trans que vivem o seu gênero, mas sem assumir ser trans, "disfarçados" de cisgênero. Geralmente, após adquirir ca- 
racterísticas masculinas suficientes para "passar como cis", os homens trans "furtivos" escolhem esse modo de viver para evitar opressões transfóbicas micro e macro ou, até mesmo, por ainda não se aceitarem como transexuais. Jackson Bird comenta:

\begin{abstract}
Não posso completamente culpar homens trans que querem ser totalmente 'stealth', quero dizer, eu sinto esse desejo em mim muito frequentemente. Porque nós vimos o que a visibilidade fez com mulheres trans: elas são contaminadas por estereótipos ridículos e violência. Homicídios transfóbicos só crescem, e a maioria das vítimas são mulheres trans de minoria étnica. (BIRD, 2019, tradução nossa)
\end{abstract}

Embora o termo seja recente, criado por jovens trans de língua inglesa, a furtividade acontece há décadas e em outros países, como é o caso dos amigos idosos que João W. Nery comenta em seu livro, como também é o caso de Lourival Bezerra, um homem que escondeu por 50 anos ter sido designado mulher ao nascer, negando o gênero feminino, ao qual não pertence, sendo "retirado do armário" apenas ao morrer, quando especialistas analisaram o corpo.

Infelizmente, as notícias que cobriram o caso, em maioria, desrespeitam a identidade do senhor de idade, apresentando-o como "uma mulher que viveu como homem e foi só descoberta ao morrer”. No entanto, graças às reclamações de familiares e pessoas trans a respeito da justiça e imprensa terem ignorado o gênero masculino do falecido, um juiz determinou que o senhor Lourival Bezerra deve ser enterrado com identidade masculina ${ }^{8}$.

\title{
Arte trans: em busca da própria representatividade
}

Como falado anteriormente, começa a crescer o número de homens trans que negam a furtividade, que querem ser vistos. Uma das maneiras de atingir olhares é a arte. Movimentos sociais utilizam historicamente a arte como expressão de suas vivências a fim de conscientizar, chamar atenção para problemas sociais, arrecadar dinheiro para doações, entre outros intuitos (MESQUITA, 2008). Com a maior democratização da arte (BENJAMIN, 2013), comunidades apagadas, inclusive entre minorias, que é o caso das pessoas trans, conseguem participar da produção artística e utilizá-la como resistência.

Mas por que falar de "arte trans"? Torna-se relevante uma vez que a utilização de imagens que retratam pessoas e vivências trans são presentes nos vídeos sobre transexualidade, nos posts de militantes, nas placas em marchas LGBTs, em tatuagens, nos ensaios fotográficos, nas campanhas de conscientização, nas camisas de coletivos.

Um dos entrevistados, Rodolfo, 23 anos, negro, baixa renda, morador de periferia belenense, acadêmico, através de suas produções artísticas procura contemplar personagens e temáticas das comunidades trans e travesti. É perceptível o papel que o corpo desempenha na sua arte, onde a nudez serve para demonstrar que se trata de uma pessoa trans, a exemplo, quando pinta uma pessoa de aparência masculina com cicatrizes abaixo do peitoral, indicando a mastectomia, realizada por alguns homens trans.

Além dos trabalhos de Rodolfo, é extensa a lista de produções artísticas que representam pessoas trans com foco em seus corpos enquanto instrumento de arte (COSTA, 2013). Se a arte pode ser usada como ferramenta de comunicação,

\footnotetext{
${ }^{8}$ Reportagem disponível em https://g1.globo.com/ms/mato-grosso-do-sul/noticia/2019/02/05/idosa-que-vivia-comohomem-usou-documento-falso-para-registrar-filhos-e-so-sera-enterrada-com-fim-do-misterio.html. Acesso em: $22 \mathrm{de}$ fevereiro de 2019.
} 
as mensagens dos artistas parecem seguir uma frequência militante, onde os artistas procuram conscientizar a população cisgênero; dar visibilidade para parcelas da comunidade trans que são apagadas; alertar sobre demandas de direito; denunciar casos de violência transfóbica, entre outras mensagens.

Semelhante à transexualidade, a arte é plural. Logo, cada forma de expressão artística possui diferenças em relação a outra. Seu público muda as mensagens que procura transmitir, seus personagens, emoções causadas. Por isso, torna-se relevante separar como a fotografia, o cinema e a ilustração representam homens transexuais.

Em relação à fotografia, os trabalhos giram em torno da normalização da nudez de corpos trans, sendo comum um certo erotismo, justificado pelo intuito de demonstrar que homens trans existem e, também, expor a beleza transmasculina. Por ser ligada, historicamente, a um senso de verdade, de demonstração da realidade, mesmo que em recortes, torna-se útil no que propõe sobre expor para o público realidades e belezas trans de forma direta, mas ainda com seu viés artístico, aqui exposto:

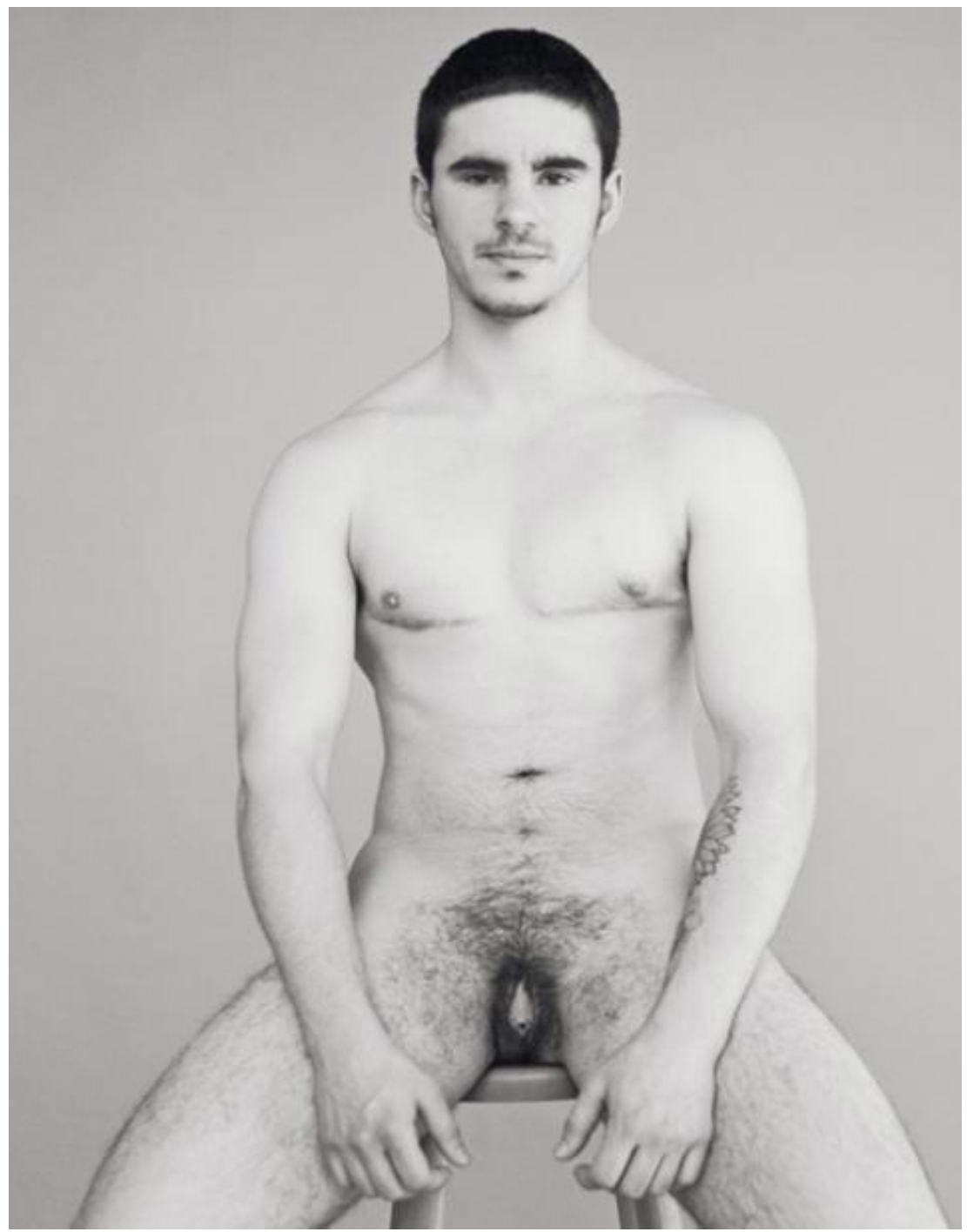

Figura 1 - Modelo Alex C. fotografado por James Mickenzie em seu projeto “Naked Sunday”. Fonte: Mickenzie, James (2016)

9 Disponível em: https://nlucon.com/2016/o9/16/18-homem-trans-alex-c-arranca-suspiros-ao-aparecer-todo-lindo-enu-em-ensaio/. Acesso em: 22/05/2019. 
Em termos de ilustração, neste termo englobando pinturas e desenhos, a sua expressão artística é mais fantasiosa, podendo não representar corpos trans, mas outros elementos culturais que indiquem se tratar de transmasculinidade. Outro elemento comum é a existência de frases desenhadas na obra, geralmente com enunciados a respeito de demandas políticas ou conselhos para outros homens trans, a exemplo:

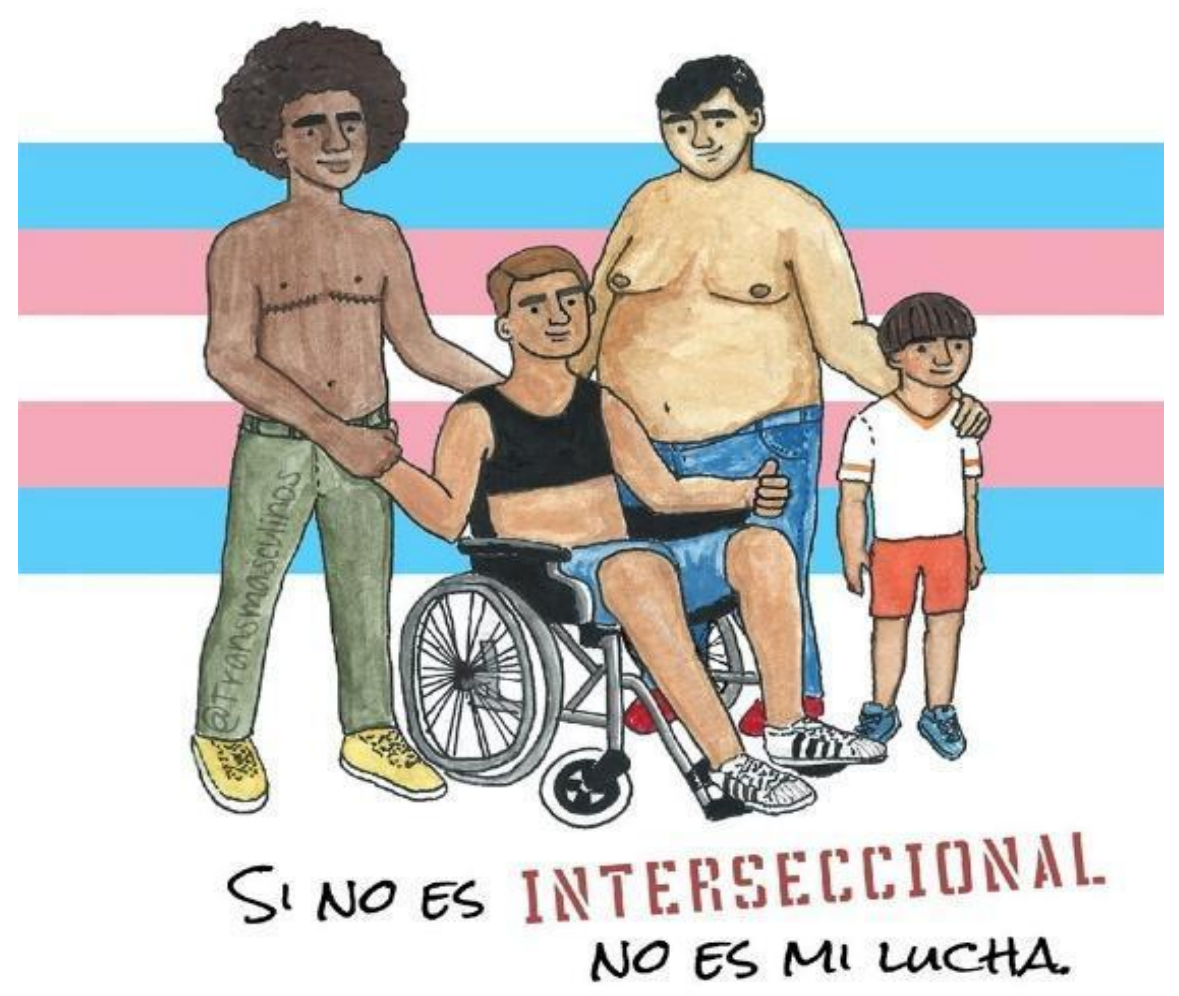

Figura 2 - "Si no es interseccional, no es mi lucha”. Fonte: Página do Facebook "Transmasculinos"10.

Abordar a relação dos homens trans com a arte surge devido a frequência com que ilustrações, pinturas e fotografias aparecem nas buscas por material de pesquisa, mas também devido ao fato de os entrevistados postarem regularmente em suas redes sociais tais trabalhos artísticos, assim como fazem páginas e contas de coletivos transmasculinos que se dedicam a postar coisas relevantes à comunidade, o que inclui os trabalhos comentados neste tópico.

A nudez nas artes trans possui um papel muito relevante, justamente um dos motivos para ser tão usada, que é a capacidade de poder informar para alguém que a pessoa retratada é trans sem precisar de elementos textuais. Como falado anteriormente, mudanças corporais não são o fator determinante para a transexualidade, a transmissão da mensagem neste caso se dá através de detalhes ligados a comunidade trans como o uso de binder, marcas de cicatrizes abaixo do peitoral, pessoa de barba e que possui vulva, entre outros.

${ }^{10}$ Disponível em: https://www.facebook.com/Transmasculinos/photos/a.1477672982338139/ 


\section{Considerações finais}

Após o levantamento de fontes físicas, digitais e entrevistas pessoais, é possível concluir que, ao longo das décadas, a comunidade transmasculina adquiriu um crescente número de locais de sociabilidades e resistências, onde garotos e homens trans conseguem utilizar espaços on-line, tais quais o Youtube, ou físicos, como reunião de coletivos para se organizar e se informar sobre assuntos pertinentes à sua comunidade, que os ajudam na sua trajetória pessoal ou política.

A cobertura de jornais a respeito da transmasculinidade, em "passos de tartaruga", foi tornando-se mais inclusiva e menos sensacionalista, embora a manchete "mulher que virou homem" ainda esteja presente em algumas matérias. Na década atual, é notável que as reportagens procuram dar voz a ativistas trans para falar sobre transexualidade e não apenas estudiosos cisgêneros.

Seja pela maior divulgação de que ser homem trans é um caminho possível, seja pela organização política dos homens trans, cresce o número de homens trans que vivem abertamente a sua transmasculinidade, lutando em movimentos sociais por medidas públicas e conscientização da sociedade sobre direitos e demandas transmasculinas. Por consequência, cresce a produção de fontes a respeito da transmasculinidade, devido a certos homens transexuais assumidos produzirem e disponibilizarem fontes como os relatos on-line, livros autobiográficos, artigos e obras de arte.

Inclusive, entre os homens trans "furtivos" houve mudanças, pois antigamente, devido às dificuldades em conseguir hormônios, era mais difícil adquirir as características masculinas necessárias para esconder sua identidade trans. Contudo, com as políticas públicas sobre saúde trans, que possibilitam a transição por hormônios pela rede pública de saúde, isso acaba por possibilitar o ganho de características masculinas, consequentemente, mais homens trans podem optar pela furtividade.

Portanto, em termos de aceitação e representatividade de homens trans e em pessoas trans como um todo, ainda é preciso passar por um longo e intenso processo de políticas públicas, protestos e participação da população cisgênero aliada à causa. No entanto, são notáveis os avanços benéficos para a representação e inclusão transmasculinas nos dias de hoje, em comparação com o século passado. Existe o crescente número de trabalhos que denunciam e demonstram as violências transfóbicas da nossa sociedade, porém, criar uma historiografia através da dor, exclusão e passividade pode ajudar, indiretamente, a criar um imaginário de pessoas trans que são apenas vítimas (LOPES, 2017). Dito isto, um dos intuitos do presente trabalho foi demonstrar como homens trans podem ser sujeitos ativos, políticos e dotados de estratégias sociais capazes de burlar um sistema transfóbico que tenta silenciar sua comunidade.

Recebido em 21 de junho de 2019.

Aprovado em 29 de novembro de 2019. 


\section{Referências}

ALMEIDA, Guilherme. "Homens trans": novos matizes na aquarela das masculinidades? Estudos Feministas, 20 (2): 513-523, 2012.

ÁVILA, Simone. FTM, transhomem, homem trans, trans, homem: a emergência de transmasculinidades no Brasil contemporâneo. Tese (Doutorado Interdisciplinar em Ciências Humanas), Centro de Filosofia e Ciências Humanas, Universidade Federal de Santa Catarina, 2014.

ARAÚJO, George Zeidan. Ler, pesquisar e escrever história em tempos de internet: desafios e possibilidades. Tempo e Argumento, 6 (12): 151-164, 2014.

BENTO, Berenice. A reinvenção do corpo: sexualidade e gênero na experiência transexual. Rio de Janeiro: Garamond, 2006.

BENTO, Berenice.; PELÚCIO, Larissa. Despatologização do gênero: a politização das identidades abjetas. Estudos feministas, 20 (2): 569-581, 2012.

BENJAMIN, W. "A obra de arte na época de sua reprodutibilidade técnica”. In: ADORNO, T. et al. Teoria da cultura de massa. São Paulo: Paz e Terra, 2000. pp. 221-254.

BUTLER, Judith. Gender trouble: Feminism and the subversion of identity. New York and London: Routledge, 2011.

CARVALHO, Bruno Leal Pastor. Faça aqui o seu login: os historiadores, os computadores as redes sociais online. Revista História Hoje, 3 (5): 165-188, 2014.

CASTEL, Pierre-Henri. Algumas reflexões para estabelecer a cronologia do "fenômeno transsexual” (1910-1995). Revista Brasileira de História, 21 (41): 77-111, 2001.

COSTA, Iracy Rúbia Vaz da. Holofotes sobre carnes: transhomens nas artes. Dissertação (Mestrado em Artes), Universidade Federal do Pará, Instituto de Ciências da Arte, 2013.

DAVANÇO, Ricardo Augusto Santana et al. Qualidade de vida e autoestima no tratamento cirúrgico da ginecomastia. Dissertação (Mestrado em Cirurgia Plástica Reparadora), Escola Paulista de Medicina, Universidade Federal de São Paulo, 2004.

DE ALMEIDA, Fábio Chang. O historiador e as fontes digitais: uma visão acerca da internet como fonte primária para pesquisas históricas. AEDOS, 3 (8): 9-30, 2011.

EIGA, Ana Maria; GUZZO, Morgani. “Trans-historizar” o espaço público dentro e fora da academia: Desafios para a historiografia e para o feminismo? Esboços Revista do Programa de Pós-Graduação em História da UFSC, 23 (35): 182209, 2016.

GASPODINI, Icaro Bonamigo et al. Masculinidades em diálogo: Produção de sentido a partir de marcadores sociais da diferença. Mudanças - Psicologia da Saúde, 25 (1): 17-25, 2017.

JESUS, Jaqueline Gomes de. Orientações sobre identidade de gênero: conceitos e termos. Goiânia: Ser-Tão/UFG, 2012. 
LEITE JR, Jorge. Nossos corpos também mudam: a invenção das categorias "travesti” e "transexual" no discurso científico. São Paulo: Annablume, 2011.

LOPES, Fábio Henrique. "Escritas de si e artes de viver transgênero: as insubordinações de uma escrita trans?” In: ALÓS, Anselmo Peres (org.). Poéticas da Masculinidade em Ruínas: amor em tempos de Aids. Santa Maria: UFSM/PPGL. pp. 127-149, 2017.

MACHADO, Paula Sandrine. Intersexualidade e o" Consenso de Chicago". As vicissitudes da nomenclatura e suas implicações regulatórias. Revista Brasileira de Ciências Sociais, 23 (68): 109-124, 2008.

MESQUITA, André Luiz. Insurgências poéticas: arte ativista e ação coletiva (1990-2000). Dissertação (Mestrado em História Social), Faculdade de Filosofia, Letras e Ciências Humanas, Universidade de São Paulo, 2008.

MISKOLCI, Richard; CAMPANA, Maximiliano. "Ideologia de gênero": notas para a genealogia de um pânico moral contemporâneo. Sociedade e Estado, 32 (3): 725-747, 2017.

MULLER, Magnor Ido; KNAUTH, Daniela Riva. Desigualdades no SUS: o caso do atendimento às travestis é 'babado'! Cadernos Ebape.br, 6 (2): 1-14, 2008.

NAPHY, William. Born to be Gay: História da Homossexualidade. Lisboa: Edições 70, 2006.

NASCIMENTO, Júlio Ferro Silva da Cunha. Violência, militância e protagonismo: a trajetória da historiografia brasileira na produção de textos trans. Canoa do Tempo, 10 (1): 52-66, 2018.

NERY, João W. Viagem solitária: memórias de um transexual 30 anos depois. São Paulo: Leya, 2011.

PIMENTEL, Adelma do Socorro Gonçalves; DE CASTRO, Ewerton Helder Bentes; MIRANDA, Davi Miranda. Compreensão fenomenológica existencial da identidade de homens trans. ECOS-Estudos Contemporâneos da Subjetividade, 8 (2): 228-239, 2018.

OLIVEIRA, Marcelo José. O Lugar do Travesti em Desterro. Dissertação (Mestrado em Antropologia Social), Centro de Filosofia e Ciências Humanas, Universidade Federal de Santa Catarina, 1997.

TUSSI, Fernanda Pivato. Toda feita: o corpo e o gênero das travestis. Horizontes Antropológicos, 12 (26): 323-327, 2006.

TOOMEY, Russell B.; SYVERTSEN, Amy K.; SHRAMKO, Maura. Transgender adolescent suicide behavior. Pediatrics, 142 (4): 1-8, 2018.

RAYMOND, Janice G.; NEVILLE, J. The transsexual empire: The making of the she-male. Boston: Beacon Press, 1979.

ROHDEN, Fabíola. "O homem é mesmo a sua testosterona”: promoção da andropausa e representações sobre sexualidade e envelhecimento no cenário brasileiro. Horizontes Antropológicos, 17 (35): 161-196, 2011.

SERANO, Julia. Whipping girl: A transsexual woman on sexism and the scapegoating of femininity. Berkeley: Seal Press, 2016. 


\section{Outras fontes}

BIRD, Jackson. Where Are All The Trans Guys? // Trans male visibility. 2019. (14mino9s). Disponível em: <https://www.youtube.com/watch?v=bFOWGD-

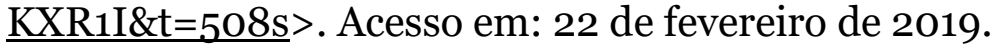

CAMINHO DA ESTANTE. Jornal do Commercio. Rio de Janeiro, ed 197, p. 4.3 junho 1985.

CONESUL NEWS. Mulher vive como homem por quase 50 anos, e identidade só é descoberta após morte. 2019. Disponível em: <http://www.conesulnews.com.br/regiao/mulher-vive-como-homem-por-quase-50-anos-e-identidade-so-e-descoberta/216394/> . Acesso em: 22 de fevereiro de 2019.

FOLHA DE SÃO PAULO. Joana ou João. São Paulo, p. 37. 27 abril 1985.

G1 PARÁ. Hospital paraense oferece primeiro atendimento hospitalar para transgêneros do Norte. 2017.2 Disponível em: $<$ https://g1.globo.com/pa/para/noticia/hospital-paraense-cria-1-ambulatoriode-transgeneros-do-norte.ghtml >. Acesso em: 22 de fevereiro de 2019.

IPEA; FUNDAÇÃO JOÃO PINHEIRO; PNUD. Desenvolvimento Humano para além das médias. 2017. Disponível em: <http://atlasbrasil.org.br/2013/data/rawData/20170530_PNUD ParaAlemdasMe-

dias alta.pdf $>$. Acesso em: 27/03/2019.

JORNAL DO BRASIL. Destino sem fatalidade. Rio de Janeiro, ed. 206. 31 outubro de 1988.

JORNAL DO BRASIL. Livro Polêmico. Rio de Janeiro, ed. 29, p. A3, 28 fevereiro 1985.

JORNAL DO BRASIL. Nas livrarias, sexo, dietas e "best-sellers". Rio de Janeiro, ed. 266, caderno b7. 31 dezembro 1834.

JORNAL DO COMMERCIO. Nas livrarias. Rio de Janeiro, ed 140, p. 16. 25 março 1985 .

MARLUN, Paulo. João, o homem que nasceu Joana. Folha de São Paulo. 2 Abril. 1985. p. 27.

MARTINELLI, Andréa. Juiz determina que Lourival Bezerra seja enterrado com identidade masculina. 2019. Disponível em: <https://www.huffpostbrasil.com/entry/lourival-justica-enterro-homem br 5c89667ce4b038892f4a0424>. Acesso em: 22 de fevereiro de 2019.

NAJAR, LUCCA. Canal de Lucca Najar. Disponível em: <https://www.youtube.com/channel/UC33ODj_jViL2YEkPM7yFoIw >. Acesso em: 22 de fevereiro de 2019.

O ESTADO DE MATO GROSSO. Programa de domingo. Mato Grosso, p. 6.3 de março, 1985 .

REZENDE, Gabriela. Idosa que vivia como homem usou documento falso para registrar filhos e só será enterrada com 'fim do mistério. 2019. Disponível em: $<$ https://g1.globo.com/ms/mato-grosso-do-sul/noticia/2019/02/05/idosa-que- 
vivia-como-homem-usou-documento-falso-para-registrar-filhos-e-so-sera-enterrada-com-fim-do-misterio.ghtml >. Acesso em: 22 de fevereiro de 2019.

ÚLTIMO SEGUNDO. Enigma sobre identidade de mulher que viveu como homem por 50 anos causa impasse. 2019. Disponível em: <https://ultimosegundo.ig.com.br/brasil/2019-02-08/mulher-viveu-como-homem-por-50anos.html >. Acessado em: 22 de fevereiro de 2019. 